\title{
PILAR BLANCO EN SU MAR DE INCERTIDUMBRES
}

JOSÉ MARÍA BALCELLS

Universidad de León

\section{Mar de silencio}

A fines de 1993 apareció la antología Ilimitada voz', en la que Aseleccionábamos poemas de autoras españolas comprendidos en el amplio marco cronológico que media entre 1940 y 2002. En esa recopilación figura la leonesa Pilar Blanco (1959), sobre la que, en la introducción que antepuse a dicho copioso elenco de versos y de poetas, escribí unas consideraciones en torno a su poética que, ciertamente, fueron confirmadas por la entrega lírica que lleva por título Mar de silencio. ${ }^{2}$

Una de las vertientes destacables de Mar de silencio es que inscribe buena porción de sus contenidos en intertextualidades referidas a las manriqueñas Coplas a la muerte de su padre, obra elegíaca que no sólo ha propiciado centenares de comentarios, sino decenas y decenas de glosas y de imitaciones, sin que falten tampoco las parodias.

El siglo XX ha sido sin duda la época en que más abundaron los textos que, en mayor o menor medida, fueron pretextados por coplas tan cimeras, las cuales darían pie a reflexiones y poemas de escritores que van desde Unamuno y Antonio Machado a Vázquez Montalbán, aunque la promoción más asociada a la estela del lírico palentino del XV ha sido la del 27, como lo atestiguan diversas composiciones poéticas o, en su caso, páginas discursivas, de Jorge Guillén, Pedro Salinas, Federico García Lorca, Luis Cernuda y Rafael Alberti.

1 Cf. José María Balcells. Ilimitada voz. Antología de poetas españolas (1940-2002). Cádiz: Universidad, 2003.

2 Cf. Pilar Blanco. Mar de silencio. Prólogo de José María Balcells. Las Palmas de Gran Canaria: Ayuntamiento, 2004. 
Un estudio muy extenso podría escribirse, en suma, a vueltas de las diversificadas gravitaciones e intertextualidades de las Coplas de Jorge Manrique en la pasada centuria. Pero los ecos del poema no han cesado en los albores del siglo XXI, como bien lo atestigua este conjunto de Pilar Blanco, una obra cuyos poemas van titulados con sendos versos de la elegía del palentino.

Aun cuando no procede comparar en sentido estricto textos tan alejados en el tiempo, y en tantos otros puntos, sí puede advertirse que la raigambre manriqueña del libro de Pilar Blanco no parece casual, ya que Mar de silencio reviste también carácter elegíaco, como el poema de Manrique, si bien circunscribe la elegía a la patética constatación del devenir temporal que afecta al género humano, sin concretarla luego en una persona en particular. En la faceta elegíaca se produce, pues, la convergencia principal entre ambas obras, que confluyen asimismo en la consideración de la fatuidad ilusoria de tantos anhelos, proyectos y aspiraciones como motivan y condicionan a una entidad tan tocada de endeblez como el hombre. Y aquí se agotan las relaciones, siendo el meollo de Mar de silencio precisamente las diferencias de fondo que distancian, de manera irreductible, ese conjunto de las Coplas.

Podemos apreciar las aludidas diferencias ya en el marco mismo de las semejanzas, porque el desengaño ante el sinsentido de tantos afanes resulta incluso mucho más drástico y patético en Pilar Blanco que en Jorge Manrique, hasta el punto de que no pocos versos de la autora leonesa los podría suscribir la ascética áurea más severa.

Sin embargo, acaso el distingo más esencial entre las Coplas y Mar de silencio radique en su frontalmente opuesta posición ante el conocimiento y la perdurabilidad. La obra del XV traduce certezas indiscutibles sobre la vida terrena y sobre otro vivir ulterior y trascendente. La de la poeta contemporánea refleja una sucesión de incertidumbres y de preguntas, y una única verdad, la del constatable y fenoménico hecho mismo de la existencia, de modo que en esta obra suya "las ansias de eternidad (...) no encuentran ningún tipo de consolación y son, por tanto, sólo causa de dolor y frustración". ${ }^{3}$

Releo ahora los párrafos referidos a Pilar Blanco en Ilimitada voz y no me cabe sino añadir que Mar de silencio supone un paso más en los caminos hipercríticos y antitrascendentalistas de esta poeta que, en este libro de gran valor lírico y conceptual, ha poetizado de nuevo, desde su nihilismo agnóstico, dudas permanentes, soledades y despojos del vivir, de un vivir atravesado por la muerte, en convergencia con la más honda de las convicciones de Antonio Gamoneda, cuya sombra "parece aletear sobre estas amargas visiones

${ }^{3}$ Cf. Manuel Parra Pozuelo, en "Mar de silencio", en El SALT (Instituto de Cultura Juan Gil Albert) 3 (enero, 2005). 
desesperadas". ${ }^{4}$ Siendo así, resultará oportuno que recordemos el texto final del libro, titulado "Mas como fuese mortal", poema dedicado precisamente al autor de Edad, y bajo cuyo título se reproduce la cita de Emily Dikinson "Latía como un mar aquel silencio":

Vencido de sí mismo, náufrago desahuciado por las olas, hondamente sentidos los rechazos más hondos, las penas más esclavas.

Y no queda el recurso de volver hacia atrás,a la infinita infancia y sus

los ojos extraviados que la sal cristaliza.

/ paisajes

El náufrago sin patria y sin pasado no conoce su cuna,

la muerte lo negó, lo condenó a la vida.

Todos náufragos siempre o alguna vez, perdidos

en mares de silencio. Las sirenas murieron. ${ }^{5}$

\section{La luz herida}

Si el lector se fija con atención en el título del conjunto de Pilar Blanco La luz herida ${ }^{6}$ y también considera los títulos bajo los cuales se han agrupado las tres secciones del libro, advertirá que dispone de cuatro indicios valiosos para captar claves esenciales de esta obra, unas claves que la autora no ha escondido, sino que ha aportado a través de dichas titulaciones.

La tesis fundamental del libro se recoge en la expresión "luz herida", mediante la que se afirma que la ilusión, la esperanza, la felicidad, la trascendencia, nociones todas susceptibles de alentar en el ámbito de la luz, están vulneradas por elementos negativos que contrarrestan la luminosidad. Establecido el aserto, la poeta organiza sus materiales a modo de una historia orientada a exponernos la radiografía de su espíritu al respecto, y nos transmite la convicción de que el asidero único para participar de la luz reside en la palabra poética.

Los tiempos en que la referida historia se despliega son tres, y se corresponden con las partes del libro: en el primero se constata cómo la luz primigenia que conlleva la vida se ve superada por la sombra, de ahí "Luz velada". En el segundo, "Entre luces", asistimos al combate por la palabra, a fin de abrir nuevos espacios de claridad. En el tercero, "Dintel de luz", ya se

\footnotetext{
4 Así lo siente José Enrique Martínez en "Alas más leves que los sueños que no logran izar nuestros huesos cansados", en Diario de León, "El Filandón” (31 de octubre de 2004).

${ }^{5}$ En Mar de silencio, op. cit., 91.

${ }^{6}$ Cf. Pilar Blanco. La luz herida. Prólogo de Antonio Gracia. Sevilla: Algaida, 2004.
} 
percibe que la luz lírica se encuentra en el umbral lumínico del que estuvo exiliada.

A tenor de este itinerario, que recuerda en síntesis los hitos esenciales de la secreta escala mística, y a su término, captamos un mensaje positivo, aunque nunca de inmoderado optimismo trascendental, hacia el que la mente de la escritora leonesa no está cerrada, pero sí es apenas proclive. Después de haber leído en muchos poetas contemporáneos de distintas generaciones y promociones diversas variantes líricas acerca de la llamada y de la aspiración de la luz, nos reafirmamos en que la singularidad del punto de vista expresado por Pilar Blanco reside en la cautela con que se va produciendo paulatinamente la aproximación al horizonte lumínico, una cautela que contrasta con la determinación, cuando no la fe, con que tantos autores esperan y fian de la luzjusticia (Rafael Alberti), de la luz-trascendencia (Ángel Crespo), de la luz de la palabra justificante (Hilario Tundidor). He recordado tan sólo a tres poetas. Podrían ser invocados bastantes más. Pero al cabo el enfoque de la problemática de la luz en La luz herida estimo que es el tan diferenciador que perfilamos.

Entre las dimensiones metafísicas de La luz herida ha de destacarse la de la temporalidad, que propicia el sentimiento elegíaco por la pérdida de la luz originaria, y que considera el existir en tres tiempos respecto a lo lumínico. También metafísica es la apertura a lo trascendente, apertura no entusiasta, sino precavida. Otra dimensión distinguible es la de índole moral, a vueltas de diversas reflexiones axiológicas.

Varios de los poetas cuya gravitación se percibe en este libro ya habían dejado sentir su influjo en conjuntos precedentes de la autora. Entre los contemporáneos, la huella más notable es la de Antonio Gamoneda7, en algún poema unida a la de José Ángel Valente ${ }^{8}$. Entre los clásicos, la de Jorge Manrique, cuyas Coplas habían hecho fructificar en gran medida Mar de silencio. Y entre la impronta de ambos reverberan lecturas esenciales de la historia de la poesía española, singularmente del período áureo, como sería el supuesto de Francisco de Quevedo, a mi juicio más emparejable con la idiosincrasia de la poeta que los versos de San Juan de la Cruz, pese a una temática que, en principio, nos orientaría hacia el carmelita. Y procede puntualizar aquí que todas las estelas implicadas en La luz herida se metabolizaron tan idóneamente que siempre las advertimos como fermento vivificador del pensar y del decir lírico de la autora, que no pocas veces moldea su voz bajo el estímulo manifiesto de aquellos ascendientes, sin que ello suponga gravamen alguno para su nítida originalidad.

\footnotetext{
7 José Enrique Martínez resaltó el factor gamonediano de La luz herida. Véanse sus observaciones al respecto en "Soñar con la luz", en Diario de León, "El Filandón" (16 de enero, 2005).

8 Cf. el comentario de Ángel Luis Luján "Intimidad barroca”, en www.arteshoy.com
} 
Uno de los retos más difíciles en literatura reside precisamente en recoger de nuevo léxico y tropología del legado escrito, a fin de dotarlos de un sentido actual, y por ende no utilizado con precedencia. Pilar Blanco muestra en este libro diversos ejemplos de tan arriesgado proceder. Elegiré uno, acaso el más significativo de la obra, hasta el punto de que revela una de las claves esenciales de la misma. Aludimos al empleo del tropo del naufragio. Ciertamente, la antedicha es una de las metáforas más socorridas, y no solo de las letras españolas, sino incluso de las occidentales. Valerse de ese vocablo, de ese concepto, de esa comparanza, supone un desafío insólito a principios del siglo XXI. Pero Pilar Blanco quiso y supo afrontar el envite, y en La luz herida se demuestra que ha salido airosa en su osadía.

Es notorio que la voz "naufragio" comporta diversidad de significaciones en este libro, pero las más sustantivas convergen en la captación del existir como naufragio a causa del exilio de la luz. De las tres partes de la obra, las dos primeras atestiguan la situación de náufragos de los seres humanos, un estado en el que la poeta insiste una y otra vez, en consonancia con una tesis muy característica, y que ya constituyó el meollo de Vocabulario íntimo (1999). ${ }^{9}$

En contraste con lo antedicho, en la tercera sección de La luz herida no se apela al naufragio más que en una única oportunidad, y aun relativa al pasado al que remite la parte inicial del libro. Esa metáfora, por consiguiente, sirve también como pauta de comprensión del sentido de este conjunto, pues en la zona espiritual del "Dintel de luz" puede encontrar el "caminante", el "peregrino" de la vida -tampoco vacila la autora en acudir a ese par de comparaciones tan tradicionales- el asidero, todavía débil, en la esperanza de la luz. Sólo queda ya el definitivo salto anímico, como parece desprenderse del último de los textos de la obra:

Ve, impulso de la luz

a la más alta

luz. ${ }^{10}$

\footnotetext{
9 Vocabulario íntimo le había merecido a su autora la siguiente explicación: "Se trata de la historia de un naufragio. Como en los clásicos, en el mar tempestuoso de nuestra propia pericia a duras penas vamos reconociendo los sucesivos leños salvadores a que aferrarnos para sobrevivir: el amor, los amigos que van quedando, la literatura, la autoestima tantas veces vencida, el ímpetu burlón que nos obliga a seguir intentándolo...Todo ello expresado unas veces a modo de reflexión y otras como diálogo con un interlocutor-pretexto que personifica muy variados fantasmas y obsesiones". Véase "Pilar Blanco Díaz", en El Filandón de El diario de León (9 de marzo de 1997).

10 En ídem, 105.
} 


\title{
Ceniza
}

Se me dirá, con toda razón, que no resulta necesario encarecer que una obra poética no tiene por qué revestir subido interés en virtud de su contenido, pues de sobra sabemos que, en poesía, no radica en este punto precisamente la calidad literaria, sino tal vez en una confluencia de factores entre los que, si fuera el caso, podría incluirse la peculiar singularidad del enfoque temático. Pero ocurre que, en mi opinión, no haríamos el debido justiprecio de Ceniza ${ }^{11}$ si no se anotara que, a la creciente valía de la palabra lírica de Pilar Blanco, y a la importancia meditativa que suele caracterizar el universo creativo de la autora leonesa, este libro añade una profundización más acusada que demanda, en condigna correspondencia por parte de los lectores, una lectura más atenta que nunca.

Y no porque encontremos determinados asuntos nuevos en el elenco de pretextos de Ceniza, sino porque Pilar Blanco ha vuelto a poetizar su original perspectiva de la vida, pero confiriéndole unos matices que constituyen auténticos hallazgos conceptuales y psicológicos, en no pocos supuestos vertidos en composiciones de textura memorable. $\mathrm{Y}$ creo que no estamos exagerando en absoluto al sostener esta meditada opinión, que basamos en poemas como el siguiente, titulado "Las riendas":

\author{
Alrededor del sueño \\ las brasas de la lluvia me cincelan la espalda \\ y cuando avanzo \\ no disipo la niebla, la conduzco ${ }^{12}$.
}

La palabra "ceniza" ha sido utilizada en más de una oportunidad en el frontis de un libro de poesía española de nuestro tiempo, siendo el de Carlos Bousoño Oda en la ceniza (1967) uno de los que primero acuden a la memoria, aunque ha habido otros, y más cercanos en el tiempo ${ }^{13}$. Pero la titulación de Pilar Blanco, en la que el vocablo se basta a sí mismo, impactándonos con toda la fuerza de su solidez sustantiva, como en su día ocurrió en la recopilación de Gamoneda titulada Edad, constituye un acierto pleno en virtud de las connotaciones de sombra inconsistente suscitadas por una voz que de manera tan apretada como sugestiva resume la precariedad de la vida humana.

La palabra "ceniza" que da título al libro comporta acepciones diversas según el campo semántico que se considere, pero en sentido figurado suele

\footnotetext{
11 Pilar Blanco. Ceniza. Madrid: Hiperión, 2005.

12 En ídem, 65.

${ }^{13}$ He aquí un par de ellos: Color ceniza el agua (1997), de José Ledesma Criado, y La edad de la ceniza (2003), de José Antonio Sáez.
} 
hacer referencia a las reliquias de un cadáver resuelto en polvo. La mención de la ceniza no conlleva trascendencia hipotética alguna, y en cambio constituye una realidad constatable a partir de la cual la autora interpreta el existir humano plasmando poéticamente sus percepciones existenciales y ontológicas sobre la vida. La manifiesta decantación de Pilar Blanco hacia la duda, así como su recelo respecto a trascendentalismos ilusorios, cuaja en esta obra de modo rotundo, y cegando resquicios a la sobrevivencia por entenderla como una fabulación compensatoria al hecho inevitable de la muerte.

No se atisba en Ceniza que haya o que no haya un más allá para los difuntos. Ni sí ni no, ni se afirma ni se niega una ulterioridad que acaso sea. Pero lo que sí deja translucir la hablante es que la conforta la incertidumbre, siéndole bien desapacibles las creencias engañosas, de suerte que ahí se origina lo que cabría denominar lirismo de la penumbra, el cual constituye una de las claves poéticas de este libro que transmite una acusada falta de confianza en lo incierto de otra clase de existencia después del existir empírico, mientras se nos sitúa poema tras poema ante el hecho patente de nuestra condición perecedera.

Y es que Ceniza no se desvía de su asunto axial en ninguna de sus tres secciones, todas presentadas bajo un lema específico que siempre remite al título del libro: "Ceniza en la memoria", "Llamas en la ceniza" y "Hoy somos noche y nada". Cabría preguntarse si los poemas incluidos en cada una de las partes del tríptico se juntaron al azar, o motivadamente. Nuestra respuesta sería que esas composiciones no fueron situadas de manera aleatoria en cada uno de los espacios, aun reconociendo que éste o aquel texto podrían ubicarse en cualquier zona de un conjunto caracterizado por la estrecha trabazón temática que lo cohesiona.

En Mar de silencio y La luz herida señalábamos la repercusión, en la obra de la escritora leonesa, de estímulos leídos en Jorge Manrique, la mística y la ascética áureas, singularmente San Juan de la Cruz y Quevedo, así como de poetas contemporáneos, sobre todo del medio siglo, a la cabeza de los cuales debe ser citado Antonio Gamoneda. En Ceniza reinciden casi todas esas gravitaciones, pero incluso se potencian las de Quevedo y Gamoneda, en coherencia con la visión de las cosas que se expresa en este conjunto.

Resulta muy pertinente, dada la índole de Ceniza, que este libro lo abra un "Frontispicio" escrito por el propio Gamoneda, y en el que se le dice a Pilar Blanco, en una suerte de epístola poemática: "La ceniza se extiende sobre negaciones invisibles", aserto que apunta a las claves implícitas de los poemas que se suceden en una obra en la que el factor gamonediano, tan perceptible en virtud del prisma adoptado, se rubrica mediante una cita del poeta que precede a los versos de la composición "Caminos del miedo".

También una cita de Quevedo se inserta en este conjunto, aunque intertextualmente modificada, en el poema "En llamas", cuya línea quinta 
principia con un "¡Ah de la muerte!" formulado como antítesis del comienzo (¡Ah de la vida!”) de un conocidísimo soneto metafísico de un escritor barroco cuyo pensamiento podría haber dejado alguna huella en distintos momentos de Ceniza, como por ejemplo en las apreciaciones vertidas en "Dique roto", donde se intersecta la idea de que el temor a la muerte supone un fuerte impedimento para que el hombre se conozca a sí mismo, idea que se propugna de vez en vez en páginas del Quevedo moralista y asceta.

Entre otras citaciones contenidas en el libro, interesa retener especialmente las de poetas españoles contemporáneos, cuyos versos se aducen a veces a modo de pretextos líricos al frente de no pocos poemas, asociándolos con ellos. Las citas aducidas son de José Hierro, J. M. Caballero Bonald, Francisco Brines, Antonio Colinas, Guillermo Carnero, Carlos Marzal y Jordi Doce. Y más incidencias poéticas afloran todavía en Ceniza, y comportándose acaso en ocasiones como meros guiños intertextuales, así el relativo a Vicente Aleixandre en el poema "Frondas" ("espinas como labios,...") y el que remite a Jaime Gil de Biedma en "Merry melodies" ("que iba la vida en serio...").

Los ascendientes, estímulos e intertextualidades que se han señalado no restan un ápice al inequívoco sello personal de Pilar Blanco que se muestra en Ceniza, uno de los libros de la escritora en los que la calidad expresiva resulta más conseguida, y en cuyos poemas se refleja más fidedignamente su idiosincrasia, porque sobre la muerte, la soledad y la nada, se ha poetizado muchísimo en la lírica contemporánea, pero apenas desde esa carencia de desazón y dramatismo con la que suelen enfocarse estas cuestiones en una poética en la que ni el vivir efímero ni un más allá incierto se pretenden trasmitir desde la angustia.

Mar de silencio, La luz herida y Ceniza guardan entre sí un parentesco muy esperable, a vueltas de su contigüidad en la trayectoria lírica de Pilar Blanco, y a vueltas asimismo de la tan estrecha perspectiva que une estos tres libros. La relación bien perceptible entre ellos no ha pasado desapercibida, leyéndose a modo de "una trilogía que cabría llamar de la negatividad existencial"14. Y se puede incluso ir más allá, entendiendo este tríptico como sustento de una etapa entera ${ }^{15}$ en la creación literaria de la escritora leonesa.

\footnotetext{
${ }^{14}$ Cf. José Enrique Martínez. "Llevo bajo los ojos un universo roto", en Diario de León 16 de octubre, 2005).

${ }^{15}$ La propia Pilar Blanco lo afirmaba: "Considero que Ceniza cierra una etapa que se abrió en Mar de silencio", en J. J. Penalva. "Belleza y vida”, en el diario Información (25 de mayo, 2006).
} 